\title{
Detection of QTL with effects on osmoregulation capacities in the rainbow trout (Oncorhynchus mykiss)
}

Yvan Le Bras ${ }^{1 \dagger}$, Nicolas Dechamp ${ }^{2 \dagger}$, Francine Krieg ${ }^{2}$, Olivier Filangi ${ }^{5,6}$, René Guyomard ${ }^{2}$, Mekki Boussaha², Henk Bovenhuis ${ }^{3}$, Thomas G Pottinger ${ }^{4}$, Patrick Prunet ${ }^{1}$, Pascale Le Roy ${ }^{5,6}$ and Edwige Quillet ${ }^{2^{*}}$

\begin{abstract}
Background: There is increasing evidence that the ability to adapt to seawater in teleost fish is modulated by genetic factors. Most studies have involved the comparison of species or strains and little is known about the genetic architecture of the trait. To address this question, we searched for QTL affecting osmoregulation capacities after transfer to saline water in a nonmigratory captive-bred population of rainbow trout.

Results: A QTL design (5 full-sib families, about 200 F2 progeny each) was produced from a cross between F0 grand-parents previously selected during two generations for a high or a low cortisol response after a standardized confinement stress. When fish were about 18 months old (near $204 \mathrm{~g}$ body weight), individual progeny were submitted to two successive hyper-osmotic challenges (30 ppt salinity) 14 days apart. Plasma chloride and sodium concentrations were recorded $24 \mathrm{~h}$ after each transfer. After the second challenge, fish were sacrificed and a gill index (weight of total gill arches corrected for body weight) was recorded. The genome scan was performed with 196 microsatellites and 85 SNP markers. Unitrait and multiple-trait QTL analyses were carried out on the whole dataset (5 families) through interval mapping methods with the QTLMap software. For post-challenge plasma ion concentrations, significant QTL $(P<0.05)$ were found on six different linkage groups and highly suggestive ones ( $P$ $<0.10$ ) on two additional linkage groups. Most QTL affected concentrations of both chloride and sodium during both challenges, but some were specific to either chloride (2 QTL) or sodium (1 QTL) concentrations. Six QTL (4 significant, 2 suggestive) affecting gill index were discovered. Two were specific to the trait, while the others were also identified as QTL for post-challenge ion concentrations. Altogether, allelic effects were consistent for QTL affecting chloride and sodium concentrations but inconsistent for QTL affecting ion concentrations and gill morphology. There was no systematic lineage effect (grand-parental origin of QTL alleles) on the recorded traits.

Conclusions: For the first time, genomic loci associated with effects on major physiological components of osmotic adaptation to seawater in a nonmigratory fish were revealed. The results pave the way for further deciphering of the complex regulatory mechanisms underlying seawater adaptation and genes involved in osmoregulatory physiology in rainbow trout and other euryhaline fishes.
\end{abstract}

\footnotetext{
* Correspondence: Edwige.Quillet@jouy.inra.fr

† Contributed equally

${ }^{2}$ INRA, UMR1313 Génétique Animale et Biologie Intégrative, F-78350 Jouy-en-

Josas, France

Full list of author information is available at the end of the article
} 


\section{Background}

The expansion of intensive aquaculture for salmonids in seawater net pens in Europe and western North America has heightened interest in genetic studies of a number of production traits in these species. Particularly well studied are aquacultured species such as rainbow trout (Oncorhynchus mykiss) which, in their wild state, include both migratory (steelhead trout) and nonmigratory (rainbow trout) forms.

Various studies have shown that rainbow trout reared in the marine environment (estuarine or coastal areas) show better growth compared to fish reared in freshwater [1-3]. Strains that naturally smoltify, a complex physiological and behavioural change that pre-adapts the fish to a high salinity environment, can be used for such purposes. However, nonmigratory populations can also be successfully adapted to, and reared in, seawater.

The ability of rainbow trout to adapt to seawater (SW) depends on the development of branchial ionoregulatory mechanisms. In a hyperosmotic environment (SW), teleost fish lose water through osmosis and gain ions (essentially $\mathrm{Na}^{+}$and $\mathrm{Cl}^{-}$) through diffusion. Maintenance of a stable hydromineral balance mainly relies on ingestion of SW coupled with active excretion of $\mathrm{Na}^{+}$and $\mathrm{Cl}^{-}$ . In freshwater (FW), the reverse mechanisms occur (see review by Evans et al. [4]). Numerous studies have investigated the activity of ion-transporters during acclimation to SW, particularly at the gill epithelium where $\mathrm{Na}^{+}$and $\mathrm{Cl}^{-}$are actively excreted in order to regulate plasma $\mathrm{Na}^{+}$and $\mathrm{Cl}^{-}$levels. These effluxes rely on branchial epithelial transporters such as $\mathrm{Na}^{+} / \mathrm{K}^{+}$-ATPase and $\mathrm{Na}^{+}-\mathrm{K}^{+}-2 \mathrm{Cl}^{-}$for $\mathrm{Na}^{+}$and CFTR for $\mathrm{Cl}^{-}$(see reviews Evans et al. [4]; Hwang and Lee [5]).

Several studies have clearly shown that the size of the fish and conditions of transfer (for example the salinity gradient) from FW to SW are key parameters for successful adaptation of rainbow trout to hyperosmotic environment $[3,6]$. Genetic factors can also contribute to the ability of fish to adapt to SW environment. Differences between two reciprocal interspecific hybrid bass populations (white bass Morone chrysops x striped bass Morone saxatilis) were shown for plasma osmolality during acclimation to salinity [7]. Differences between lagoon and marine sea bass (Dicentrarchus labrax) before and after freshwater acclimation have also been reported by Allegrucci et al. [8]. The inheritance of smoltification has been examined in several salmonid species including steelhead trout (the migratory form of rainbow trout) [9-11]. These studies suggest that both the timing and propensity to smoltification are under genetic control. Similar findings have been reported for migratory (anadromous) and nonmigratory populations of Atlantic salmon (Salmo salar). Surveys of landlocked Atlantic salmon from North America and Europe, and of landlocked and anadromous populations have shown differences in the capacity of these strains to adapt to SW [12-16] and the analysis of osmoregulatory mechanisms at the level of gill has shown that differential expression of gill $\mathrm{Na}^{+} / \mathrm{K}^{+}$-ATPase $-\alpha 1 \mathrm{a},-\alpha 1 \mathrm{~b}$ and $-\alpha 3$ isoforms associated with $\mathrm{Na}^{+} / \mathrm{K}^{+}$-ATPase activity may account for these differences in osmoregulatory performance [17].

The recent development of genetic resources in rainbow trout, including genetic markers and medium density genetic maps [18-21] provides the foundation for deeper biological understanding of the genetic basis of phenotypic patterns of importance for aquaculture. The identification of QTL (Quantitative Trait Loci) paves the way for a precise investigation of the molecular genetic basis of traits. While many QTL studies have already been implemented for a range of traits, including growth [22], disease resistance [23-26], temperature tolerance [27], cortisol responsiveness [28] and early maturation [29], very little has been done regarding osmoregulation capacities in rainbow trout. Nichols et al. [10] performed a QTL study for smoltification-related traits using a cross between nonmigratory (rainbow) and migratory (steelhead) trout lines. However, the study mainly focused on growth and morphological traits (body shape, skin reflectance) while no significant QTL was detected for the gill $\mathrm{Na}^{+} / \mathrm{K}^{+}$-ATPase activity, a key branchial epithelial $\mathrm{Na}^{+}$transporter.

In this study, we transferred rainbow trout from FW to SW and performed a QTL analysis for plasma $\mathrm{Na}^{+}$ and $\mathrm{Cl}^{-}$levels, which are the standard physiological parameters used to characterize the ability of fish to adapt to a hyperosmotic environment [30-32]. In addition, we were also interested in gill size which could be a factor in salinity adaptation. A QTL design was produced using rainbow trout lines previously selected for high (HR) or low (LR) cortisol responsiveness to an acute confinement stressor [33]. Cortisol is a major hormone regulating stress responses but also a major osmoregulatory hormone. Though mechanisms induced by confinement and salinity stressors may not be the same, the HR and LR lines differ in the responsiveness of the corticotrope axis and thus represented highly relevant biological material for this QTL experimental design.

\section{Methods}

\section{Experimental design and fish rearing conditions}

Grand-parental brood stock belonged to two O. mykiss lines (HR and LR), previously selected for divergent plasma cortisol responsiveness to a standardized confinement stressor $[33,34]$. F1 parents were produced by mating single individuals within the second generation of selected HR and LR individuals, one from each line. 
The next generation, five F1 males and five F1 females were single pair mated in order to produce the five F2 full sib families used for QTL detection (denoted X3, $\mathrm{X} 4, \mathrm{X} 8, \mathrm{X} 14$ and X17). All fish (F0, F1 and F2 families) were maintained at the $\mathrm{CEH}$ (Centre for Ecology \& Hydrology) experimental fish facilities (Windermere, UK).

Fertilization was performed in January, 2006, employing standard stripping and fertilization methods. When the fish were about 11 months old, 215 individuals per family were randomly sampled, individually tagged with passive integrated transponders (PIT; Trovan ID100A), fin clipped for further DNA extraction and distributed into ten holding tanks (1000 litres), with each family held in two tanks. Each tank was supplied with a constant flow of lake water $(25 \mathrm{~L} / \mathrm{min})$ at ambient temperature. The fish were monitored closely and fed approx $2 \%$ body weight, 3 days per week (Skretting Standard Expanded 40). As part of the EU Aquafirst project, fish were submitted to two successive confinement stressors when they were about 15 months old. At the end of the confinement challenge, each family was distributed into holding tanks at a similar density (around 40 to 50 fish per tank, i.e. 5 to 6 tanks per family depending on the family size). Fish were allowed to recover until the commencement of the osmotic challenge (18 months old).

The experimental work at $\mathrm{CEH}$ Windermere was carried out under the UK Animals (Scientific Procedures) Act 1986, Project Licence no. 40/2600.

\section{Osmotic challenge and measurements}

Each fish was tested twice with 14 days between challenges. Exposure to salt water was carried out in a series of 20 plastic tanks that were filled with 150 litres of lake water containing 4500 g Red Sea Coral Reef Salt (30 ppt) and continuously aerated and fitted with an opaque lid. The contents of a single holding tank (40 to 50 fish) were accommodated in four salinity test tanks allowing the contents of four holding tanks to be tested on each working day. The fish were transferred on day 1 and, as osmotic stress acclimation is a temporal process, they were sampled exactly 24 h later, on day 2 , corresponding to the time required for the maximum acclimatory response. Fish were netted from the salinity test tanks and anaesthetized in buckets containing 2-phenoxyethanol (1:2000) before being blood sampled and identified by PIT tag. Blood was collected from the Cuverian sinus into heparinised syringes and plasma was stored frozen until required for determination of plasma chloride and sodium concentrations. Fish were returned to their holding tanks to recover. During the first test, body weight and fork length were recorded for each fish.

Plasma sodium and chloride levels were measured by flame photometry (VWR international, Fontenay-sous- bois, France) and by colorimetry (chlorure LDM SOBIODA $\left.^{(}\right)$[35] respectively. Plasma samples were diluted 1:400 and 1:2 with distilled water for the analysis of sodium and chloride respectively and analyses were performed in duplicate and triplicate respectively. Sodium values from the first and second challenge were identified as $\mathrm{Na}^{+} 1$ and $\mathrm{Na}^{+} 2$ respectively, and the corresponding chloride values were denoted $\mathrm{Cl}^{-} 1$ and $\mathrm{Cl}^{-} 2$.

Fish were sacrificed about 2 months after the end of the second challenge. At that time, the whole body weight, the weight of gill archs (including gill filaments and cartilage) and sex (macroscopic examination of the gonads) were recorded for the remaining individuals. An index of relative gill weight, named gill index (gill weight corrected for body weight used as covariable) was included in the present study, with the intention of investigating possible links between gill size and osmoregulation capacities. Indeed, a preliminary survey of gill morphology in 40 fish from HR and LR lines revealed that LR individuals had larger gill arches in term of weight and surface area. It was assumed that the individual relative gill weight remains stable across short periods of time and at the time of terminal sampling was still representative of the morphology at the time of osmotic challenge.

\section{Genotyping and genetic map}

The genome scan was performed using microsatellites and SNP markers. Microsatellites were chosen from the INRA reference linkage maps [19]. In a first step, 201 microsatellites chosen on the basis of their map position were screened for polymorphism in the original HR and LR lines, and a sub-set of 138 was retained for further genotyping. In a second step, in order to improve the genome coverage within every family, additional markers were selected in genomic regions still poorly covered and were tested for polymorphism in the five QTL families. In the end, a set of 196 microsatellites, including 13 duplicated markers, was used. Among those, 49 were genotyped by LABOGENA (Jouy-en-Josas, France) while the others were genotyped at INRA-GABI. SNP markers designed by Krieg et al. (in preparation) were screened for polymorphism in the QTL families and 85 (see GenBank dbSNP submission numbers in Additional file 1) were retained for the genome scan and genotyped by Genoscope using SNPlex Genotyping System (Applied Biosystem). The overall polymorphism information content (PIC) of markers was 0.51 for microsatellites and 0.30 for SNP. The mean PIC per linkage group ranged from 0.32 to 0.65 .

The genetic consensus linkage map was rebuilt for the families of the QTL design including the whole set of markers and using the CarthaGène software ([36], http://www.inra.fr/internet/Departements/MIA/T// 
CarthaGene/). The total length of the map was 3182 $\mathrm{cM}$, so that the mean overall spacing for genome coverage was about $16 \mathrm{cM}$ (3 to 16 markers per linkage group; 179 to 206 informative markers per family). Linkage groups were named according to Guyomard et al. [19], with correspondence with physical chromosomes according to Phillips et al. [20] indicated in tables and figures.

\section{Statistical analyses \\ Description of traits}

We first provided some description of the raw data for the five traits of interest $\left(\mathrm{Na}^{+} 1, \mathrm{Na}^{+} 2, \mathrm{Cl}^{-} 1, \mathrm{Cl}^{-} 2\right.$ and gill index) and determined whether the rank of challenge (first $v s$ second challenge) on one hand and the different families on the other hand significantly affected the traits. The significance of these two factors was tested using the GLM procedure, SAS version 9 [37] at the $\mathrm{P}<$ 0.05 level.

\section{Sources of variability}

In order to choose a model for further analyses, the effects of several fixed effects and co-factors were tested for every trait. The GLM procedure, SAS version 9 [37] was applied to an overall model which included tested factors and the full-sib family effect. For plasma ion values $\left(\mathrm{Na}^{+} 1, \mathrm{Na}^{+} 2, \mathrm{Cl}^{-} 1, \mathrm{Cl}^{-} 2\right)$ the overall model was:

$\mathrm{Y}_{\mathrm{ijklmn}}=\mu+\operatorname{Sex}_{\mathrm{i}}+$ Date $_{\mathrm{j}}+\operatorname{Htank}(\text { date })_{\mathrm{jk}}+$ Ctank $_{\mathrm{l}}+$ Cross $_{\mathrm{m}}+\beta_{1} *$ weight $+\beta_{2} *$ length $+\mathrm{e}_{\mathrm{ijklmn}}$

where

$\mathrm{Y}_{\mathrm{ijklmn}}$ is the progeny phenotype (plasma ion values) $\mu$ is the general mean of the model

Sex $_{\mathrm{i}}$ is the fixed effect of sex $\mathrm{i}$ with 2 levels (male and female)

Date $_{j}$ is the fixed effect of the date $j$ of challenge (6 levels)

Htank(date $)_{j k}$ is the fixed effect of the holding tank $k$ within date $\mathrm{j}$ (21 levels)

Ctank $_{1}$ is the fixed effect of the challenge tank 1 (20 levels)

Cross $_{m}$ is the fixed effect of the full-sib family $m$ ( 5 levels)

weight is the body weight at the first challenge considered as a covariable

length is the fork length at the first challenge considered as a covariable

and $e_{i j k l m n}$ is the residual of the model supposed normally distributed with a mean 0 and a variance $\sigma_{\mathrm{e}}^{2}$.

For gill weight, the model was adapted to take into account further changes in the management of fish between the end of challenge and measurements of sex and gill weight.

$\mathrm{Y}_{\mathrm{ijk} \mathrm{m}}=\mu+\operatorname{Sex}_{\mathrm{i}}+$ Group $_{\mathrm{j}}+\mathrm{Htank}_{\mathrm{k}}+$ Cross $_{1}+\beta_{1} *$ weight $+\beta_{2} *$ length $+\mathrm{e}_{\mathrm{ijklm}}$

where

$\mathrm{Y}_{\mathrm{ijklm}}$ is the progeny gill weight value

$\mu$ is the general mean of the model

$\operatorname{Sex}_{\mathrm{i}}$ is the fixed effect of sex $\mathrm{i}$ with 2 levels (male and female)

Group $_{j}$ is the fixed effect of the date $j$ at weighing (2 levels, as after challenge 2 , fish were redistributed in 2 groups that were terminally sampled with several weeks delay)

Htank $k_{k}$ if the fixed effect of the holding tank k (12 levels)

Cross $_{1}$ is the fixed effect of the full-sib family 1 (5 levels)

weight is the body weight at the date of measurement considered as a covariable

length is the fork length at the date of measurement considered as a covariable

and $e_{i j k l m}$ is the residual of the model supposed normally distributed with a mean 0 and a variance $\sigma_{\mathrm{e}}{ }^{2}$.

Factors having a P-value equal to or less than 0.2 in these pre-analyses were kept in the final models. Model (1) for ion plasma concentrations revealed that all effects but sex and fork length were significant at the 0.20 level. Model (2) for gill weight indicated that body weight, sex (males having heavier gills than females) and Group were significant at the 0.20 level. Thus, the final models used in further analyses were as follows:

For plasma ion concentrations (both challenges):

$$
\mathrm{Y}_{\mathrm{ijkl}}=\mu+\text { date }_{\mathrm{i}}+\mathrm{Htank}\left(\text { date }_{\mathrm{ij}}+\mathrm{Ctank}_{\mathrm{k}}+\beta_{1} * \text { weight }+\mathrm{e}_{\mathrm{ijk}}\right.
$$

For gill index:

$$
\mathrm{Y}_{\mathrm{ijk}}=\mu+\operatorname{sex}_{\mathrm{i}}+\text { Group }_{\mathrm{j}}+\beta_{1} * \text { weight }+\mathrm{e}_{\mathrm{ijk}}
$$

\section{Phenotypic correlations}

Models (3) and (4) were applied to adjust raw data for fixed effects and co-factors using the SAS GLM procedure. The Pearson coefficients of correlation were then determined with the CORR procedure, SAS version 9 [37] applied on residual values of these models (phenotypic correlations).

\section{QTL detection}

QTLMap software [38] was used for QTL detection, scanning for QTL every $1 \mathrm{cM}$ in the genome. An interval mapping method described by Elsen et al. [39] was applied considering a set of non-related full-sib families design 
and making no assumption about allele numbers or allele frequencies at QTL within founder populations. QTL effects are thus estimated, for each sire and each dam, as the allelic substitution effects. The statistical test used to compare the hypotheses of the presence of one QTL (H1) vs no QTL (H0) at one location was an approximate likelihood ratio test (LRT) [40]. The empirical distribution of LRT was obtained from 1000 simulations under the null hypothesis, with a trait heritability fixed to 0.5 , for each trait and each linkage group. Thresholds of $\mathrm{HO}$ rejection at the chromosome-wide level (P-values $=0.005,0.01,0.05$ and 0.10$)$ were then estimated with the method described by Harrel and Davis [41]. A QTL with a P-value $<0.10$ at the chromosome-wide level was retained as suggestive, and a QTL with a P-value $<0.05$ at the chromosome-wide level was retained as significant [42]. The widely used "one LOD drop-off method" was applied to obtain 95\% confidence intervals of the QTL location [43]. Finally, the status of the sires and dams for QTL (heterozygous vs homozygous) was tested using a t-test $(\mathrm{P}<0.05)$. As grand-parents had been genotyped, the lineage origin, i.e. HR or LR, of each QTL allele of heterozygous parent could be deduced.

In a first step, univariate analyses were carried out trait by trait. Multiple-trait QTL analyses were performed in a second step. We applied a multivariate model with a multinormal penetrance distribution, which is the most powerful and accurate method [44]. In both unitrait and multiple-trait analyses, the phenotypic models (3) and (4) were given as input of the QTLMap software for the analysis of raw data.

\section{Results}

Traits description

The number of recorded individuals, family means, overall means and standard deviations of the different traits (raw data) are given in Table 1.
Figure 1 illustrates the effect of the challenge (first $v s$ second challenge), with a marked increase of plasma sodium concentrations during the second challenge relative to the first $(+8.5 \%$ in average, $\mathrm{P}<0.01$, from +5.7 to $+10.7 \%$ depending on the family) whereas chloride concentrations were lower during the second challenge $(-1.2 \%$ in average, $\mathrm{P}<0.05$, from $-10 \%$ to $+5 \%$ depending on the family) than during the first. Significant family differences $(P<0.01)$ were found only for gill index and $\mathrm{Na}^{+} 2$. For other plasma ion concentrations $\left(\mathrm{Na}^{+} 1, \mathrm{Cl}^{-} 1\right.$ and $\left.\mathrm{Cl}^{-} 2\right)$, family effect was not significant ( $\mathrm{P}>0.05)$.

\section{Phenotypic correlations}

As shown in Table 2, the phenotypic correlation between the values of sodium and chloride concentrations at the two challenges was high for sodium (Pearson coefficient of correlation $\mathrm{R}=0.67$ ) but low for chloride $(R=0.08)$. Within challenge, the phenotypic correlation between sodium and chloride concentrations was moderate $(R=0.21)$. No significant phenotypic correlation was detected between gill index and any of the plasma ion concentrations.

\section{QTL detection}

\section{Results of unitrait analyses}

Unitrait analyses highlighted the existence of seven significant $(\mathrm{P}<0.05)$ and seven suggestive $(\mathrm{P}<0.10)$ QTL. Ten QTL affected plasma ion concentrations (six suggestive and four significant) and four affected gill index (one suggestive and three significant, Table 3 ).

The four significant QTL for plasma ion concentrations were distributed on four different linkage groups (RT10, RT14, RT25 and RT26). Linkage group RT14 accommodated QTL for $\mathrm{Na}^{+} 2(\mathrm{P}<0.05)$ and probably for $\mathrm{Na}^{+} 1$ also $(\mathrm{P}<0.10)$, but there was no overlap

Table 1 Mean body traits and ion plasma concentrations at the two successive osmotic challenges

\begin{tabular}{|c|c|c|c|c|c|c|c|c|c|}
\hline \multirow[t]{2}{*}{ Traits } & \multirow[t]{2}{*}{ Unit } & \multicolumn{5}{|c|}{ Family mean } & \multirow[t]{2}{*}{ Overall mean } & \multirow[t]{2}{*}{ SD } & \multirow[t]{2}{*}{$\mathrm{n}$} \\
\hline & & X3 & $\mathrm{X} 4$ & $\mathrm{X} 8$ & $\mathrm{X} 14$ & $\mathrm{X} 17$ & & & \\
\hline $\mathrm{Na}^{+} 1$ & $\mathrm{mmol}^{-\mathrm{L}^{-1}}$ & 185 & 195 & 209 & 186 & 191 & 193 & 27 & 932 \\
\hline $\mathrm{Na}^{+} 2$ & & 204 & 207 & 221 & 206 & 200 & 208 & 35 & 900 \\
\hline $\mathrm{Cl}^{-1}$ & & 147 & 144 & 156 & 140 & 139 & 145 & 17 & 931 \\
\hline $\mathrm{Cl}^{-2}$ & & 147 & 142 & 141 & 148 & 138 & 143 & 15 & 894 \\
\hline Body weight at challenge 1 & $g$ & 203 & 200 & 210 & 190 & 214 & 204 & 9 & 932 \\
\hline Fork length at challenge 1 & $\mathrm{~cm}$ & 26.6 & 25.7 & 26.5 & 26.2 & 26.7 & 26.3 & 0.4 & 932 \\
\hline Final gill weight & $g$ & 10.8 & 10 & 10.8 & 9.6 & 11.0 & 10.4 & 2.6 & 787 \\
\hline Final body weight & & 423 & 382 & 433 & 381 & 434 & 411 & 98 & 791 \\
\hline
\end{tabular}

$\mathrm{Na}^{+} 1, \mathrm{Na}^{+}$2: plasma sodium concentration at first and second challenge respectively.

$\mathrm{Cl}^{-1}$, $\mathrm{Cl}^{-2}$ : plasma chloride concentration at first and second challenge respectively.

Final gill weight and body weight measured 2 months after the end of the second challenge.

SD: overall standard deviation; $\mathrm{n}$ : total number of individual records. 


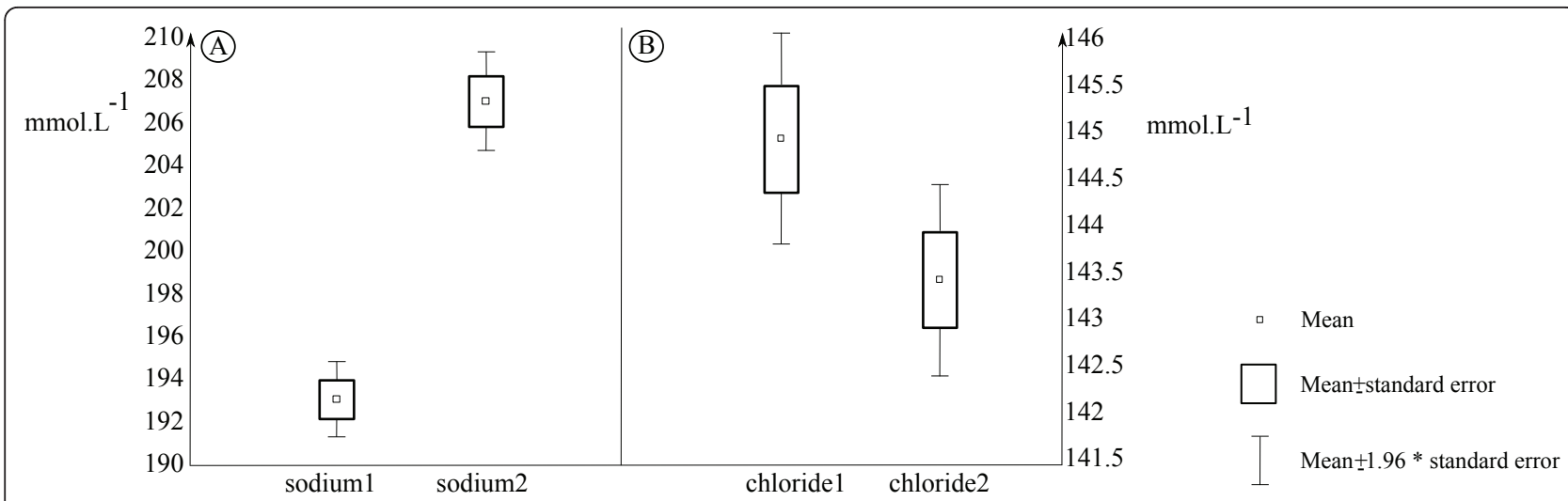

Figure 1 Boxplot representation of sodium (A) and chloride- (B) plasma concentrations at the two successive osmotic challenges.

between the QTL locations, indicating that the QTL involved in the first challenge, if confirmed, may not have been the same as in the second challenge. Two QTL were associated with $\mathrm{Cl}^{-1} 1$ (RT25 and RT26), and one QTL was associated with $\mathrm{Cl}^{-2}$ (RT10). The QTL located on RT10 was the most significant $(\mathrm{P}<0.01)$. No common QTL between the two successive challenges was detected for either $\mathrm{Cl}^{-}$or $\mathrm{Na}^{+}$concentrations. Overall, QTL for sodium and chloride concentrations were localized in different regions of the genome. Yet, at the second challenge, suggestive QTL detected on RT19 for $\mathrm{Na}^{+} 2$ and $\mathrm{Cl}^{-} 2$ overlapped suggesting the existence of a QTL possibly affecting both traits.

Significant QTL for plasma ion concentrations segregated in at least 3 families of the design, and up to 7 heterozygous parents were detected for some QTL. Most often, the QTL allele that increased sodium or chloride concentrations originated from the LR grand-

Table 2 Pairwise coefficients of phenotypic correlation among the different traits

\begin{tabular}{|c|c|c|c|c|c|}
\hline Traits & & gill index & $\mathrm{Cl}^{-2}$ & $\mathrm{Cl}^{-1} 1$ & $\mathrm{Na}^{+} 2$ \\
\hline \multirow[t]{3}{*}{$\mathrm{Na}^{+} 1$} & $R$ & 0.00 & 0.03 & 0.21 & 0.67 \\
\hline & $P$ & 0.98 & 0.31 & $<0.0001$ & $<0.0001$ \\
\hline & $n$ & 776 & 862 & 901 & 871 \\
\hline \multirow[t]{3}{*}{$\mathrm{Na}^{+} 2$} & $\mathrm{R}$ & 0.06 & 0.22 & 0.13 & \\
\hline & P & 0.12 & $<0.0001$ & 0.0001 & \\
\hline & $n$ & 771 & 865 & 867 & \\
\hline \multirow[t]{3}{*}{$\mathrm{Cl}^{-1} 1$} & $R$ & 0.01 & 0.08 & & \\
\hline & P & 0.69 & 0.02 & & \\
\hline & $n$ & 772 & 858 & & \\
\hline \multirow[t]{3}{*}{$\mathrm{Cl}^{-2} 2$} & $\mathrm{R}$ & 0.04 & & & \\
\hline & P & 0.24 & & & \\
\hline & $n$ & 762 & & & \\
\hline
\end{tabular}

R: Pearson coefficient of correlation between individual records corrected for fixed effects and co-factors; $P$ : associated P-value; $\mathrm{n}$ : number of individual records. parent (16 cases out of 23 significant allelic contrasts for RT10, RT14, RT25 and RT26, see Table 3). The QTL alleles that increased gill index were equally distributed among the LR and HR genetic lineage (Table 3), though the lineage effect may differ according to the locus (increasing effect of HR alleles at RT9 and RT15 and decreasing effect on RT26 and RT27).

Most QTL for gill index were found on linkage groups different from those harbouring QTL for plasma ion concentrations, with the exception of RT26 where a QTL for $\mathrm{Cl}^{-1} 1$ overlapped the QTL for gill index. In the only parent where the comparison was possible, the same QTL allele increased both gill index and $\mathrm{Cl}^{-1}$ plasma concentration.

Mean QTL effects ranged from 0.29 to 0.55 phenotypic standard deviation. The largest allelic effects were identified for chloride concentrations (more than 0.8 phenotypic SD in some families).

\section{Results of multiple-trait analyses}

Altogether, multiple-trait analyses detected six significant QTL and eleven suggestive ones (Table 4).

For ionic concentrations, multiple-trait analyses confirmed the existence and location of several of the QTL previously detected in unitrait analysis (RT10, RT26, RT19). It evidenced that those QTL steadily affected the target trait in the two successive challenges or consistently affected both sodium and chloride concentrations. Thus, the highly significant QTL on RT10 for chloride concentration at the second challenge was confirmed at the first challenge $\left(\mathrm{Cl}^{-} 1-\mathrm{Cl}^{-} 2\right.$ multiple-trait analysis, Table 4), and multiple-trait analysis also revealed an effect of this QTL on sodium concentration at both challenges $\left(\mathrm{Na}^{+} 2-\mathrm{Cl}^{-} 2\right.$ and 4-traits analysis of plasma ions). In the 2-traits analysis for challenge 2, this QTL was significant at the genome-wide level $(\mathrm{P}<0.05)$. Similarly, the effect of the QTL on RT19 on both chloride and sodium concentrations was underlined. While in unitrait analyses, this QTL was suggestive for the two 
Table 3 QTL detected after unitrait analyses for gill index and ion plasma concentrations $24 \mathrm{~h}$ after an osmotic challenge at 30 ppt salinity

\begin{tabular}{|c|c|c|c|c|c|c|c|c|}
\hline \multirow[t]{2}{*}{ Trait } & \multirow[t]{2}{*}{ LG $(C h r)^{a}$} & \multirow[t]{2}{*}{ Max LRT $^{b}$} & \multirow[t]{2}{*}{ Position $^{c}$} & \multirow[t]{2}{*}{$\mathrm{Cl}^{\mathrm{d}}$} & \multicolumn{2}{|c|}{ QTL effect ${ }^{e}$} & \multicolumn{2}{|c|}{$n_{H}{ }^{f}$} \\
\hline & & & & & mean & $\min -\max$ & LR & $\mathrm{HR}$ \\
\hline \multirow[t]{3}{*}{$\mathrm{Na}^{+} 1$} & RT14 (Omy19) & 22.1 & 66 & $60-72$ & 0.33 & $0.26-0.47$ & 4 & 1 \\
\hline & RT29 (Omy17) & 23.3 & 55 & $52-60$ & 0.34 & $0.22-0.55$ & 4 & 1 \\
\hline & RT31 (Omy3) & 22.8 & 4 & $0-14$ & 0.31 & $0.22-0.49$ & 4 & 2 \\
\hline \multirow[t]{2}{*}{$\overline{\mathrm{Na}^{+} 2}$} & RT14 (Omy19) & $28.9^{*}$ & 0 & $0-10$ & 0.45 & $0.24-0.64$ & 2 & 1 \\
\hline & RT19 (Omy11) & 22.3 & 119 & $115-119$ & 0.30 & $0.21-0.38$ & 5 & 2 \\
\hline \multirow[t]{2}{*}{$\overline{\mathrm{Cl}^{-1} 1}$} & RT25 (Omy29) & $25.1^{*}$ & 12 & $6-19$ & 0.29 & $0.20-0.43$ & 5 & 2 \\
\hline & RT26 (Omy24) & $22.8^{*}$ & 43 & $27-55$ & 0.30 & $0.20-0.48$ & 6 & 0 \\
\hline \multirow[t]{3}{*}{$\mathrm{Cl}^{2}$} & RT10 (Omy6) & $31.2^{* *}$ & 21 & $18-24$ & 0.41 & $0.21-0.83$ & 3 & 4 \\
\hline & RT19 (Omy11) & 22.7 & 112 & 88-119 & 0.34 & $0.26-0.56$ & 4 & 2 \\
\hline & RT21 (Omy9) & 21.7 & 32 & $0-44$ & 0.47 & $0.29-0.57$ & 2 & 1 \\
\hline \multirow[t]{4}{*}{ Gill index } & RT9 (Omy12) & $28.6^{* *}$ & 75 & $70-80$ & 0.45 & $0.28-0.58$ & 1 & 3 \\
\hline & RT15 (Omy21) & $23.2^{*}$ & 51 & $40-51$ & 0.33 & $0.20-0.49$ & 1 & 4 \\
\hline & RT26 (Omy24) & $24.7^{*}$ & 43 & $35-50$ & 0.55 & $0.38-0.89$ & 3 & 0 \\
\hline & RT27 (Omy2) & 22.4 & 6 & $0-20$ & 0.31 & $0.22-0.53$ & 4 & 2 \\
\hline
\end{tabular}

a: linkage groups according to Guyomard et al. [19] and corresponding physical chromosomes (Chr) according to Phillips et al. [20].

b: maximum likelihood test value (LRT) and corresponding chromosome-wide significance level (no indication: $\mathrm{P}<0.10$; ${ }^{*}: \mathrm{P}<0.05 ;{ }^{* *}$ : $\mathrm{P}<0.01$ ).

c: position on the consensus linkage group rebuilt with the families of the design.

${ }^{d}$ : confidence interval of the position estimated with the 'drop off' method.

e: QTL substitution effect (in phenotypic standard deviation of the trait). Mean, min and max refer respectively to the mean, minimum and maximum QTL effects recorded among families with significant QTL effect at $P<0.05$.

$f: n_{H}$ is the number of $F 1$ parent segregating for the QTL. LR and HR indicate the line having transmitted the allele with an increasing effect on the trait.

traits at the second challenge, it became significant in the 2-traits analysis, and the 4-traits analysis also suggested it may be involved at the first challenge. The QTL for chloride concentration on RT26, which was detected in unitrait analysis for the first challenge only, was found again $(\mathrm{P}<0.10)$ for both $\mathrm{Cl}^{-1} 1$ and $\mathrm{Cl}^{-} 2$ in multiple-trait analysis. For those three QTL (RT10, RT19 and RT26), locations of the QTL revealed in the different analyses were quite consistent (Table 3). Results of multiple-trait analysis also confirmed that RT14 harbours QTL affecting sodium concentrations at both challenges. However, locations did not support the hypothesis of a single QTL for all traits (two QTL at 0 and $66 \mathrm{cM}$ in unitrait analysis, and one QTL at $27 \mathrm{cM}$ in multiple-trait analysis, with no overlap). Further testing for the presence of 2 QTL $v s 1$ QTL on the linkage group did not support the presence of 2 distinct QTL (data not shown).

Novel QTL affecting plasma ion concentrations were discovered (RT4, RT5, RT7, RT9, RT23) though most of them, with the exception of QTL on RT4, were suggestive only $(\mathrm{P}<0.10)$. Nevertheless, two of them were detected in several multiple-trait analyses at very consistent locations (RT5, RT23). All newly discovered QTL affected concentrations of both ions (sodium and chloride). Two of them were specific to the challenge (QTL on RT7 for challenge 1 and QTL on RT9 for challenge 2 ), but were significant at $\mathrm{P}<0.10$ only.
In summary, considering both significance levels and consistency of the different analyses, QTL for plasma ion concentrations were detected on the linkage groups RT4, RT10 and RT19 (both chloride and sodium concentrations at both challenges), RT26 (chloride concentration at both challenges), RT25 (chloride concentration at the first challenge) and RT14 (sodium concentration at both challenges) though no consistent QTL location could be found on that linkage group.

Allelic effects at the different QTL tended to be consistent for both ions, i.e. an allele that increased chloride concentration also increased sodium concentration, but opposite were also observed (often for an allelic effect near the significance threshold). For the three significant QTL affecting both ion concentrations (RT4, RT10, RT19), QTL allelic effects were consistent for both ions in 13 out of the 16 cases where the comparison was possible. Allelic effects on plasma ion concentrations also varied according to QTL and genetic lineage. While HR alleles tended to decrease chloride and sodium concentrations at QTL on linkage groups RT19 and RT26 as previously observed in unitrait analysis, they tended to be mostly associated with higher plasma concentrations at QTL on RT5, RT9 and RT23. Mean allelic effects were in the same range as in unitrait analyses (0.3-0.35 phenotypic SD). Again, the highest values were recorded for chloride concentrations (around 0.8 SD in some families, data not shown). 


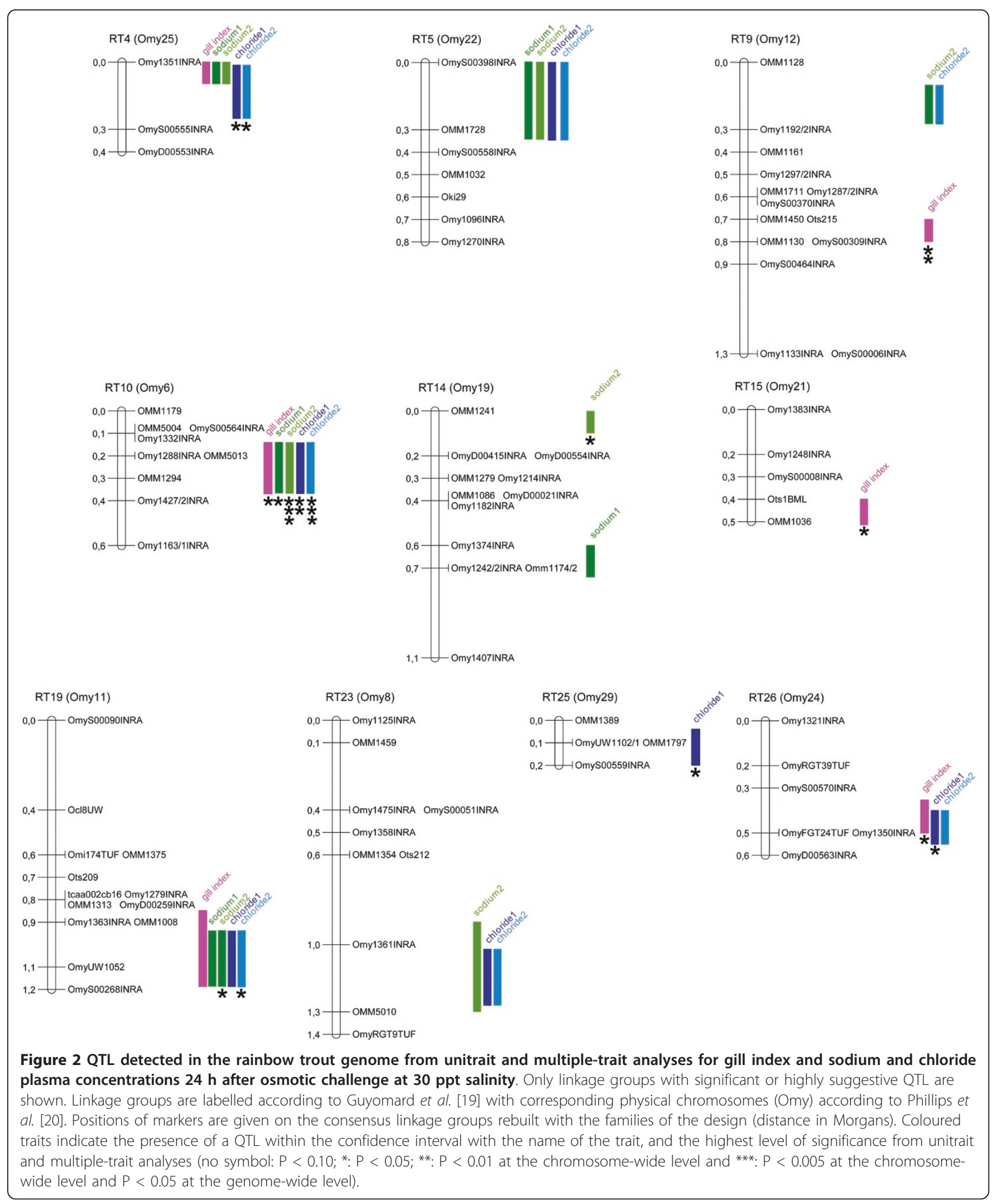


indicators of the hydromineral balance after an osmotic challenge in a euryhaline fish. Our results strengthen and extend previous studies which suggested that genetic factors are likely to influence the ability to adapt to high salinity in teleost fish. These studies were based on the comparison of different species and their hybrids (as in sea bass [7] or in tilapia [45]) or on the comparison of different strains or populations in teleost fish on striped bass [8], salmon [13,14,16,17,46] and artic charr (Salvelinus alpinus) [15]. The discovery of QTL associated with osmoregulatory ability in rainbow trout paves the way for further understanding of the genetic basis of the regulatory mechanisms and physiological pathways involved in the control of hydromineral balance in this species.

We identified several QTL contributing to the variation of plasma ion concentrations after exposure to the salinity challenge. The plasma levels of chloride and sodium, the two main ions responsible for plasma osmotic pressure, are key indicators of the regulation of hydromineral balance and consequently were chosen to monitor the adaptation to 30 ppt salinity in the QTL progenies.

Two significant QTL (on RT10 and RT19) and four suggestive QTL (on RT4, RT5, RT9 and RT23) were found to control the variation of both ions during the two successive challenges. Moreover, in most cases, the QTL affected both concentrations in the same direction. There are no data about the value of the genetic correlation between the two ion concentrations in the plasma and the genetic structure of our sample (5 full-sib families) did not allow a reliable estimate of it. Nonetheless, this result is consistent with our observation that the individual plasma values of $\mathrm{Na}^{+}$and $\mathrm{Cl}^{-}$are significantly correlated within each challenge. It is also consistent with our present understanding of the hypoosmoregulatory mechanisms in seawater which indicate that the extrusion of $\mathrm{Na}^{+}$and $\mathrm{Cl}^{-}$is accomplished by distinct but coupled mechanisms. The current model for $\mathrm{NaCl}$ extrusion at the gill epithelium proposes a basolateral cotransport of $\mathrm{Na}^{+}$and $\mathrm{Cl}^{-}$down the electrochemical gradient produced by NKCC co-transporter. This co-transport is coupled with an apical extrusion of $\mathrm{Cl}^{-}$via a low conductance anion channel and a paracellular extrusion of $\mathrm{Na}^{+}$through $\mathrm{Na}^{+}-\mathrm{K}^{+}$-ATPase transporter and diffusion towards the external medium down its electrochemical gradient (see reviews Evans et al. [4]; Hwang and Lee [5]). The morpho-functional modification of the gill epithelium characterized by the development of leaky junctions and also accessory cells are fundamental for efficient extrusion of $\mathrm{Cl}^{-}$and $\mathrm{Na}^{+}$in the gill [47]. Whether these common QTL correspond to genes encoding major regulators of these cellular changes would be an interesting hypothesis to test.
We also found QTL affecting the concentration of one only of the two ions. For sodium, the most significant QTL affected ionic concentration at the second challenge $(\mathrm{P}<0.05)$, and was located on RT14. For chloride, one QTL was consistently found on RT26, and an additional QTL may be located on RT25 ( P $<0.05$, in unitrait analysis only). Taken together, the levels of significance of those QTL remain moderate and the power of our design may have impeded the detection of some effect on the alternative ion. Nevertheless, this result may also indicate that the regulation of plasma sodium and chloride relies in part on ion-specific mechanisms. Based on the present knowledge of the cellular mechanisms responsible for $\mathrm{Na}^{+}$and $\mathrm{Cl}^{-}$extrusion in hyperosmotic environment (see review Marshall and Bellamy [48]), one may hypothesise an association between QTL and one of the ion transporters characterized at the level of the gill epithelium. Additional information may have come from the genes in which the SNP used for the genome scan have been detected although examination of the known biological function of these genes (Gene Ontology) did not suggest any gene relevant for its involvement in ion or water exchange at the level of transporting epithelia.

The QTL families were F2 progenies from two divergent grand-parental lines (HR and LR) previously selected for plasma cortisol response to an acute confinement stress [33,34]. It is well established that cortisol plays an important role in the success of the adaptive osmoregulation process after transfer to a saline environment [49]. Cortisol represents a major endocrine actor in the regulation of ionic homeostasis, particularly after environmental salinity change, by regulating some seawater specific ion transporters such as $\mathrm{Na}^{+}-\mathrm{K}$ ${ }^{+}$-ATPase isoforms, NKCC and CFTR [49-56]. By its actions on gill chloride cells number and activity, cortisol acts in synergy with IGF-1 and GH to increase overall salinity tolerance (see review by McCormick [51]). Yet, altogether, our QTL results do not support evidence of a unidirectional association between the HR vs LR origin of QTL alleles and their effect on ion concentrations in the plasma. They rather suggest that the role of grand-parental alleles depends on the loci, a result that highlights the functional complexity of underlying mechanisms and is in agreement with the present knowledge that different stressors (as confinement or salinity stressors) have distinct effects on the physiological mechanisms regulated by cortisol [57]. However, by introducing a valuable source of additional variability in comparison to a standard within-population QTL design, the HR and LR fish provide a valuable tool with which to obtain a better understanding of the complex hormonal control of hypo-osmoregulatory mechanisms. An increasing amount of attention is paid to welfare 
and robustness traits in aquaculture, and many studies on the genetic control of cortisol response to stressors have been carried out, ultimately concerned with reducing stress in farmed fish [28,57,59-62]. Thus, a better understanding of the relationship between cortisol responsiveness to acute stress and osmoregulation capacities is a key requirement prior to the adoption of any selection programme designed to manage the cortisol response to stress in aquacultured fish.

Preliminary observations had suggested that LR individuals had relatively larger gill arches than HR individuals. The QTL design was thus appropriate to search for QTL for gill relative development. Four significant and two suggestive QTL were detected for gill weight relative to body weight. This result is in agreement with other studies that have identified the existence of numerous QTL for body traits in fish [62-64]. Four of those QTL are also involved in the regulation of plasma $\mathrm{Na}^{+}$and $\mathrm{Cl}^{-}$concentration after the osmotic challenge, which raises the question of the possible role of gill size and morphology on osmoregulatory capacities. To our knowledge there are no published data indicating any genetic correlation between gill size and tolerance to high salinity, and the genetic structure of the QTL data set (5 full sib families) did not allow a reliable estimate to be calculated. However, we observed that the QTL alleles associated with a larger gill also affected ionic concentrations in the plasma in different directions (increase as decrease). The total weight of gill arches is not directly representative of the relative development of the gill epithelium, which is the active site for ionic and water exchange and it is therefore unlikely that there is a direct 'mechanical' effect of gill size, through an increase of the branchial ion-exchange surface. This is also in agreement with the lack of correlation between individual values for gill index and any of the plasma ion concentrations in the different challenges. The most likely hypothesis is that QTL harbour multiple syntenic genes regulating the morphological trait (gill size) and physiological traits (ionic concentrations).

Up to now, very few studies have investigated the genetic architecture of osmoregulation capacity or associated traits in salmonids. To our knowledge, only Nichols et al. [10] have searched for QTL associated with migratory capacities (smoltification) in trout O. mykiss. Using a cross between nonmigratory rainbow trout and migratory steelhead trout line, they discovered 14 genomic regions (on 14 different linkage groups) associated with smoltification-related morphological traits (growth, condition factor, body coloration, morphology). The genome scan in this study was performed using AFLP markers, but at least one microsatellite per linkage group was genotyped and can be used to establish synteny with other rainbow trout maps. Interestingly, several QTL discovered in the two studies co-localize on the same rainbow trout linkage groups. This is the case for the QTL on linkage groups RT9, RT14 and RT23 for which we could establish the synteny with respectively OC9, OC14 and OC23 in Nichols et al. Ambiguity remains for the QTL located respectively on OC3 in Nichols et al. and RT25 in this study. In Nichols et al., OC3 is identified by One8ASC and Ogo2. These two markers belong to a region homologous to RT25, as attested by several shared duplicated loci, including Ogo2 [19,21]. This suggests that the two aforementioned QTLs could be under control of two homeologous genes. Furthermore, since the duplicated or non-duplicated status of One8ASC (as any marker) is difficult to prove and can vary among populations, the possibility that OC 3 and RT 25 correspond to the same linkage group in these two particular studies cannot be ruled out. Two additional QTL suggestive in the present study (RT21 and RT31) also locate on linkage groups identified in Nichols et al. For RT21, the synteny can be established from Omy325DU (on OC21 in the study by Nichols et al.) and Omy325UoG (on RT21 in our linkage map [19]), which correspond in fact to the same marker (R. Danzmann, personal communication).

On the other hand, it is worth emphasising that in our study, we do not find any salinity acclimation QTL on RT20, the linkage group the most strongly associated with smoltification traits (mostly growth and morphological traits) in the study of Nichols et al. As no smoltification process occurred in the fish during our survey, this observation is not surprising. It emphasizes that the smoltification process and the adaptation to salinity after a direct transfer to seawater are two different processes.

Overall, there are at least three linkage groups (and possibly 6) harbouring QTL in both studies. It is very difficult to compare the location of the QTL discovered in the two studies on the linkage groups, as genome scans were performed with a low marker density and different types of markers were used (AFLP vs microsatellites). Moreover, the traits recorded in the two studies are quite different (survey of growth and changes in body colour and morphology over the time course of smoltification $v s$ plasma indicators of the status of the hydromineral balance after an osmotic challenge in a nonmigratory population) and many linkage groups are found to harbour QTL for the traits examined in the two studies (10 and 14 in the present study and the one by Nichols et al. respectively). Although it is thus possible that common linkage groups are observed by chance, these observations may also substantiate the role of those genomic regions in the osmoregulatory process in trout and corroborates the hypothesis that some of the key processes for the control of hydromineral balance during adaptation to salinity (as highlighted by our QTL study) also occur in individuals undergoing smoltification. 
During this experiment, a large number of individual fish were submitted twice to the same salinity stressor. The data set provides additional information on basic physiological responses of trout during the early (first 24 hours) adaptation to seawater. The mean plasma ion concentrations were in the same range as those usually recorded in similar tests with fish of similar sizes. However, when the fish were exposed twice to the salinity challenge ( $24 \mathrm{~h}$ at $30 \mathrm{ppt}$ salinity) separated by a 2 week recovery period, plasma $\mathrm{Na}^{+}$and $\mathrm{Cl}^{-}$levels did not behave similarly: we observed an increase in the mean plasma $\mathrm{Na}^{+}$levels between the first and second challenges whereas no major changes were observed in plasma $\mathrm{Cl}^{-}$levels (Table 1). It is possible that this difference is linked to the fact that, in rainbow trout, plasma $\mathrm{Na}^{+}$level changes after transfer to SW were much more sensitive than plasma $\mathrm{Cl}^{-}$level changes ([30]; Brard et al., unpublished data) and this requires further investigation. These results also suggest that, at least for $\mathrm{Na}^{+}$, an acute salinity stressor (24 h exposure to $30 \mathrm{ppt}$ salinity) may lead to permanent modification of the functionality of the $\mathrm{Na}^{+}$osmoregulatory mechanisms resulting in a change in the capacity to excrete $\mathrm{Na}^{+}$ when the fish is re-exposed to high salinity. To our knowledge, such a mechanism has never been reported in the literature.

\section{Conclusions}

To summarize, we have identified several regions of the rainbow trout genome that are associated with the ability to regulate hydromineral balance after a salinity challenge. These are first findings that will undoubtedly be refined in the future as the current development of genomic tools and markers in rainbow trout will allow the use of a higher marker density and performance of genome-wide analyses. Nevertheless, the results highlight the complexity of physiological and hormonal mechanisms that underlie these processes and provide an original insight into the genetic bases of the early stages of adaptation to seawater. They also lay the foundation for further investigations and a better understanding of this complex trait.

\section{Additional material}

Additional file 1: GenBank dbSNP submission numbers of the SNP used in the genome scan.

\section{Acknowledgements}

Authors wish to thank a number of persons for their helpful contribution to the project. David Abel provided technical assistance at CEH (Windermere, UK). At INRA, Stéphane Mauger, Amandine Launay and Ludivine Laffont contributed to microsatellite genotyping, Caroline Hervet helped to select markers, genotype and control genotypes quality and to prepare the linkage analyses in QTL families, André Neau helped in data management. Dominique Brunel and Aurélie Bérard (CNG, Centre National de Genotypage, Evry, France) adjusted the SNPlex technology to trout samples. Tehui Wang (Scottish Fish Immunology Research Centre, School of Biological Sciences, University of Aberdeen, UK) supervised the final phenotyping (sex, body and gill weight) in the Scottish Fish Immunology Research Centre facilites. This study was funded by the European Commission (project AQUAFIRST, contract number FP6-STREP-2004-513692), the Natural Environment Research Council of the United Kingdom, INRA (Institut national de la Recherche Agronomique, France), la Région Bretagne (Aquagene project, contract number 2450) and MESR (Ministère de l'Enseignement Supérieur et de la Recherche, France; contract number 26907-2007)

\section{Author details}

${ }^{1}$ INRA, UR1037 SCRIBE, IFR 140, F-35000 Rennes, France. ${ }^{2}$ INRA, UMR1313 Génétique Animale et Biologie Intégrative, F-78350 Jouy-en-Josas, France. ${ }^{3}$ Animal Breeding and Genetics Group, Wageningen University, P.O. Box 338, NL-6700AH, Wageningen, The Netherlands. ${ }^{4}$ Centre for Ecology \& Hydrology, Lancaster Environment Centre, Bailrigg, Lancaster LA1 4AP, UK. ${ }^{5}$ INRA, UMR0598 Génétique Animale, F-35000 Rennes, France. ${ }^{6}$ Agrocampus Ouest, UMR0598 Génétique Animale, F-35000 Rennes, France.

\section{Authors' contributions}

YLB and ND performed the QTL analyses. YLB carried out part of the plasma assays and drafted the manuscript. FK carried out the whole SNP subset of the genome scan and participated in the organisation of the overall genome scan and the generation of linkage maps. OF wrote severals adaptations of the program for the QTL detection in this protocole. RG participated in critically analysing genetic maps. MB assisted in the building of the maps. HB participated in the choice of the QTL family design. TPG supervised the production and management of fish, carried out the salinity challenge and sampling. PP designed the salinity test and shared the drafting of the manuscript. PLR wrote update versions of the QTLMap software, supervised QTL analyses and participated in drafting the manuscript. EQ conceived of the whole study, participated in its design and coordination and was involved in drafting the manuscript. All authors read and approved the final manuscript.

Received: 3 April 2011 Accepted: 14 May 2011 Published: 14 May 2011

\section{References}

1. Sedgwick SD: Rainbow trout farming in Scotland. Farming trout in salt water. Scott Agric 1970, 49:180-185.

2. Landless PJ: Acclimation of rainbow trout to seawater. Aquaculture 1976 7:173-179.

3. Johnston CE, Cheverie JC: Comparative analysis of ionoregulation in rainbow trout (Salmo gairdneri) of different sizes following rapid and slow salinity adaptation. Can J Fish Aquat Sci 1985, 42:1994-2003.

4. Evans DH, Piermarini PM, Choe KP: The multifunctional fish gill: Dominant site of gas exchange, osmoregulation, acid-base regulation, and excretion of nitrogenous waste. Physiol Rev 2005, 85:97-177.

5. Hwang PP, Lee TH: New insights into fish ion regulation and mitochondrion-rich cells. Comp Biochem Physiol A Mol Integr Physiol 2007, 148:479-497.

6. Fuentes J, Soengas JL, Buceta M, Otero J, Rey P, Rebolledo E: Kidney ATPase response in seawater-transferred rainbow trout (Oncorhynchus mykiss). Effect of salinity and fish size. Rev Esp Fisiol 1996, 52:231-238.

7. Myers JJ, Kohler CC: Acute responses to salinity for sunshine bass and Palmetto bass. N Am J Aquacult 2000, 62:195-202.

8. Allegrucci G, Caccone A, Cataudella S, Powell JR, Sbordoni V: Acclimation of the European sea bass to freshwater: monitoring genetic changes by RAPD polymerase chain reaction to detect DNA polymorphisms. Mar Biol 1995, 121:591-599.

9. Johnsson Jl, Clarke WC, Blackburn J: Hybridization with domesticated rainbow-trout reduces seasonal-variation in seawater adaptability of steelhead trout (Oncorhynchus mykiss). Aquaculture 1994, 121:73-77.

10. Nichols KM, Edo AF, Wheeler PA, Thorgaard GH: The genetic basis of smoltification-related traits in Oncorhynchus mykiss. Genetics 2008, 179:1559-1575.

11. Thrower F, Guthrie C, Nielsen J, Joyce J: A comparison of genetic variation between an anadromous steelhead, Oncorhynchus mykiss, population 
and seven derived populations sequestered in freshwater for 70 years. Environ Biol Fishes 2004, 69:111-125.

12. Birt TP, Green JM, Davidson WS: Contrasts in development and smolting of genetically distinct sympatric anadromous and nonanadromous Atlantic salmon, Salmo salar. Can J Zool 1991, 69:2075-2084.

13. Birt TP, Green JM: Acclimation to seawater of dwarf nonanadromous Atlantic salmon, Salmo salar. Can J Zool 1993, 71:1912-1916.

14. Staurnes M, Lysfjord G, Berg OK: Parr-smolt transformation of a nonanadromous population of Atlantic salmon (Salmo salar) in Norway. Can J Zool 1992, 70:197-199.

15. Schmitz M: Seasonal changes in hypoosmoregulatory ability in landlocked and anadromous populations of Arctic charr, Salvelinus alpinus, and Atlantic salmon, Salmo salar. Environ Biol Fishes 1995, 42:401-412.

16. Nilsen TO, Ebbesson LOE, Stefanson SO: Smolting in anadromous and landlocked strains of Atlantic salmon (Salmo salar). Aquaculture 2003, 222:71-82.

17. Nilsen TO, Ebbesson LOE, Madsen SS, McCormick SD, Andersson E, Bjornsson BT, et al: Differential expression of gill $\mathrm{Na}+, \mathrm{K}+-\mathrm{ATPase}$ \{alpha\}and \{beta\}-subunits, $\mathrm{Na}+, \mathrm{K}+, 2 \mathrm{Cl}$ - cotransporter and CFTR anion channel in juvenile anadromous and landlocked Atlantic salmon Salmo salar. J Exp Biol 2007, 210:2885-2896.

18. Nichols KM, Young WP, Danzmann RG, Robison BD, Rexroad C, Noakes M, Phillips RB, Bentzen P, Spies I, Knudsen K, Allendorf FW, Cunningham BM, Brunelli J, Zhang $\mathrm{H}$, Ristow S, Drew R, Brown $\mathrm{KH}$, Wheeler PA, Thorgaard GH: A consolidated linkage map for rainbow trout (Oncorhynchus mykiss). Anim Genet 2003, 34:102-115.

19. Guyomard R, Mauger S, Tabet-Canale K, Martineau S, Genet C, Krieg F, Quillet E: A type I and type II microsatellite linkage map of rainbow trout (Oncorhynchus mykiss) with presumptive coverage of all chromosome arms. BMC Genomics 2006, 7:30.

20. Phillips RB, Nichols KM, DeKoning JJ, Morasch MR, Keatley KA, Rexroad C, Gahr SA, Danzmann RG, Drew RE, Thorgaard GH: Assignment of rainbow trout linkage groups to specific chromosomes. Genetics 2006, 174:1661-1670.

21. Rexroad C, Palti Y, Gahr S, Vallejo R: A second generation genetic map for rainbow trout (Oncorhynchus mykiss). BMC Genetics 2008, 9:74.

22. Wringe BF, Devlin RH, Ferguson MM, Moghadam HK, Sakhrani D, Danzmann RG: Growth-related quantitative trait loci in domestic and wild rainbow trout (Oncorhynchus mykiss). BMC Genetics 2010, 11:63.

23. Zimmerman A, Evenhuis J, Thorgaard G, Ristow S: A single major chromosomal region controls natural killer cell-like activity in rainbow trout. Immunogenetics 2004, 55:825-835

24. Rodriguez MF, LaPatra S, Williams S, Famula T, May B: Genetic markers associated with resistance to infectious hematopoietic necrosis in rainbow and steelhead trout (Oncorhynchus mykiss) backcrosses. Aquaculture 2004, 241:93-115.

25. Khoo SK, Ozaki A, Nakamura F, Arakawa T, Ishimoto S, Nickolov R, Sakamoto T, Akutsu T, Mochizuki M, Denda I, Okamoto N: Identification of a novel chromosomal region associated with infectious hematopoietic necrosis (IHN) resistance in rainbow trout Oncorhynchus mykiss. Fish Pathol 2004, 39:95-101.

26. Ozaki A, Khoo SK, Yoshiura Y, Ototake M, Sakamoto T, Dijkstra JM, Okamoto N: Identification of additional Quantitative Trait Loci (QTL) responsible for susceptibility to infectious pancreatic necrosis virus in rainbow trout. Fish Pathol 2007, 42:131-140.

27. Perry GML, Ferguson MM, Sakamoto T, Danzmann RG: Sex-linked Quantitative Trait Loci for thermotolerance and length in the rainbow trout. J Hered 2005, 96:97-107.

28. Drew RE, Schwabl H, Wheeler PA, Thorgaard GH: Detection of QTL influencing cortisol levels in rainbow trout (Oncorhynchus mykiss). Aquaculture 2007, 272:S183-S194.

29. Haidle L, Janssen JE, Gharbi K, Moghadam HK, Ferguson MM, Danzmann RG: Determination of quantitative trait loci (QTL) for early maturation in rainbow trout (Oncorhynchus mykiss). Mar Biotechnol (NY) 2008, 10:579-592.

30. Hoar WS: Osmotic and ionic regulation. In General and comparative physiology. Edited by: Hoar WS. Prentice-Hall New Jersey (USA); 1983:627-658

31. Prunet $P$, Boeuf $G$, Houdebine LM: Plasma and pituitary prolactin levels in rainbow trout during adaptation to different salinities. J Exp Zool 1985, 235:187-196
32. Tanguy $J M$, Ombredane $D$, Baglinière $J$, Prunet $P$ : Aspects of parr-smolt transformation in anadromous and resident forms of brown trout (Salmo trutta) in comparison with Atlantic salmon (Salmo salar). Aquaculture 1994, 121:51-63.

33. Pottinger TG, Carrick TR: Modification of the plasma cortisol response to stress in rainbow trout by selective breeding. Gen Comp Endocrinol 1999, 116:122-132.

34. Overli O, Winberg S, Pottinger TG: Behavioral and neuroendocrine correlates of selection for stress responsiveness in rainbow trout: a review. Integr Comp Biol 2005, 45:463-474.

35. Schoenfeld RG, Lerveller CV: Colorimetric method for determination of serum chloride. Clin Chem 1964, 10:553.

36. de Givry S, Bouchez M, Chabrier P, Milan D, Schiex T: CARTHAGENE: multipopulation integrated genetic and radiation hybrid mapping. Bioinformatics 2005, 21:1703-1704

37. The SAS Institute: SAS/STAT User's Guide, Version 9. Cary, NC, SAS Institute Inc; 2002.

38. Filangi O, Moreno C, Gilbert H, Legarra A, Le Roy P, Elsen JM: QTLMap, a software for QTL detection in outbred populations. Proceedings of the 9th World Congress on Genetics Applied to Livestock Production:1-6 August; Leipzig 2010, n787.

39. Elsen JM, Mangin B, Goffinet B, Boichard D, Le Roy P: Alternative models for QTL detection in livestock. I. General introduction. Genet Sel Evol 1999, 31:213-224.

40. Le Roy P, Elsen JM, Boichard D, Mangin B, Bidanel JP, Goffinet B: An algorithm for QTL detection in mixture of full and half sib families. Proceedings of the 6th World Congress on Genetics Applied to Livestock Production; Armidale 1998, 257-260.

41. Harrel FE, Davis CE: A new distribution-free quantile estimator. Biometrika 1982, 69:635-640.

42. Lander $E$, Kruglyak L: Genetic dissection of complex traits: guidelines for interpreting and reporting linkage results. Nat Genet 1995, 11:241-247.

43. Lander ES, Botstein D: Mapping Mendelian factors underlying quantitative traits using RFLP linkage maps. Genetics 1989, 121:185-199.

44. Gilbert H, Le Roy P: Comparison of three multitrait methods for QTL detection. Genet Sel Evol 2003, 35:281-304.

45. Yan B, Wang Z: Growth, salinity tolerance and microsatellite analysis of the $F_{2}$ reciprocal hybrids of Oreochromis niloticus $\times$ Sarotherodon galilaeus at different salinities. Aquac Res 2010, 41:336-344

46. Handeland SO, Björnsson BTh, Arnesen AM, Stefansson SO: Seawater adaptation and growth of post-smolt Atlantic salmon (Salmo salar) of wild and farmed strains. Aquaculture 2003, 220:367-384.

47. Kaneko T, Watanabe S, Lee KM: Functional morphology of mitochondrionrich cells in euryhaline and stenohaline teleosts. Aqua-BioSci Monogr 2008, 1:1-62

48. Marshall WS, Bellamy D: The $\mathbf{5 0}$ year evolution of in vitro systems to reveal salt transport functions of teleost fish gills. Comp Biochem Physiol A Mol Integr Physiol 2010, 155:275-280.

49. McCormick SD, Regish A, O'Dea MF, Shrimpton JM: Are we missing a mineralocorticoid in teleost fish? Effects of cortisol, deoxycorticosterone and aldosterone on osmoregulation, gill $\mathrm{Na}+, \mathrm{K}+-\mathrm{ATP}$ ase activity and isoform mRNA levels in Atlantic salmon. Gen Comp Endocr 2008, 157:35-40

50. Lin H, Pfeiffer D, Vogl A, Pan J, Randall D: Immunolocalization of $\mathrm{H}$ ${ }^{+}$-ATPase in the gill epithelia of rainbow trout. J Exp Biol 1994, 195:169-183.

51. McCormick SD: Endocrine control of osmoregulation in teleost fish. Am Zool 2001, 41:781-794.

52. Kiilerich $\mathrm{P}$, Kristiansen $\mathrm{K}$, Madsen SS: Cortisol regulation of ion transporter mRNA in Atlantic salmon gill and the effect of salinity on the signaling pathway. J Endocrinol 2007, 194:417-427.

53. McCormick SD, Bern HA: In vitro stimulation of Na+-K+-ATPase activity and ouabain binding by cortisol in coho salmon gill. Am J Physiol 1989, 256:R707-R715

54. Tipsmark CK, Madsen SS, Seidelin M, Christensen AS, Cutler CP, Cramb G: Dynamics of $\mathrm{Na}(+), \mathrm{K}(+), 2 \mathrm{Cl}(-)$ cotransporter and $\mathrm{Na}(+), \mathrm{K}(+)$-ATPase expression in the branchial epithelium of brown trout (Salmo trutta) and Atlantic salmon (Salmo salar). J Exp Zool 2002, 293:106-118.

55. Shrimpton JM, McCormick SD: Responsiveness of gill Na+/K+-ATPase to cortisol is related to gill corticosteroid receptor concentration in juvenile rainbow trout. J Exp Biol 1999, 202:987-995. 
56. Deane EE, Woo NYS: Differential gene expression associated with euryhalinity in sea bream (Sparus sarba). Am J Physiol Regul Integr Comp Physiol 2004, 287:R1054-R1063.

57. Wendelaar Bonga SE: The stress response in fish. Physiol Rev 1997, 77:591-625.

58. Kettunen A, Serenius T, Fjalestad KT: Three statistical approaches for genetic analysis of disease resistance to vibriosis in Atlantic cod (Gadus morhua L.). J Anim Sci 2007, 85:305-313.

59. Weber GM, Silverstein JT: Evaluation of a stress response for use in a selective breeding program for improved growth and disease resistance in rainbow trout. N Am J Aquacult 2007, 69:69-79.

60. Weber GM, Vallejo RL, Lankford SE, Silverstein JT, Welch TJ: Cortisol response to a crowding stress: Heritability and association with disease resistance to Yersinia ruckeri in rainbow trout. N Am J Aquacult 2008, 70:425-433.

61. Vallejo RL, Rexroad CE III, Silverstein JT, Janss LL, Weber GM: Evidence of major genes affecting stress response in rainbow trout using Bayesian methods of complex segregation analysis. J Anim Sci 2009, 87:3490-3505.

62. Massault C, Hellemans B, Louro B, Batargias C, Van Houdt JK, Canario A, Volckaert FAM, Bovenhuis H, Haley C, De Koning DJ: QTL for body weight, morphometric traits and stress response in European sea bass Dicentrarchus labrax. Anim Genet 2010, 41:337-345.

63. Reid DP, Szanto A, Glebe B, Danzmann RG, Ferguson MM: QTL for body weight and condition factor in Atlantic salmon (Salmo salar): comparative analysis with rainbow trout (Oncorhynchus mykiss) and Arctic charr (Salvelinus alpinus). Heredity 2005, 94:166-172.

64. Moghadam H, Poissant J, Fotherby H, Haidle L, Ferguson M, Danzmann R: Quantitative trait loci for body weight, condition factor and age at sexual maturation in Arctic charr (Salvelinus alpinus): comparative analysis with rainbow trout (Oncorhynchus mykiss) and Atlantic salmon (Salmo salar). Mol Genet Genomics 2007, 277:647-661.

doi:10.1186/1471-2156-12-46

Cite this article as: Le Bras et al:: Detection of QTL with effects on osmoregulation capacities in the rainbow trout (Oncorhynchus mykiss). BMC Genetics 2011 12:46.

\section{Submit your next manuscript to BioMed Central and take full advantage of:}

- Convenient online submission

- Thorough peer review

- No space constraints or color figure charges

- Immediate publication on acceptance

- Inclusion in PubMed, CAS, Scopus and Google Scholar

- Research which is freely available for redistribution

Submit your manuscript at www.biomedcentral.com/submit 